Andrade, C.O.P.; Carvalho, R.C.R.; Godinho, R.F.; Magri, R.A.F. Elaboração e aplicação de uma rota de trekking em uma área do Parque Nacional da Serra da Canastra. Revista Brasileira de Ecoturismo, São Paulo, v.9, n.2, mai/jul 2016, pp.285-317.

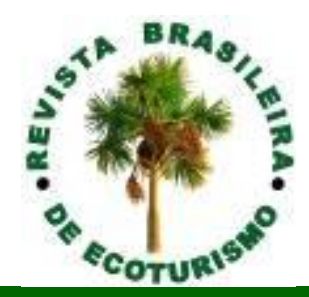

\title{
Elaboração e aplicação de uma rota de trekking em uma área do Parque Nacional da Serra da Canastra
}

\author{
Development and application of a hiking trail an area of Serra da \\ Canastra National Park
}

\author{
Conrado Oliveira de Pádua Andrade, Rita de Cássia Ribeiro Carvalho, \\ Ricardo Ferreira Godinho, Rômulo Amaral Faustino Magri
}

\section{RESUMO}

O Cerrado brasileiro é o segundo maior bioma do Brasil, e se espalha por oito Estados diferentes, o que desempenha um papel crucial na questão dos recursos hídricos. A região do estudo da pesquisa é uma área remanescente de 130 mil hectares de Cerrado, que desde 1972 vem passando por constantes problemas fundiários em decorrência da tentativa ineficiente do Governo Brasileiro de implantar uma Unidade de Conservação na área. Enquanto esse processo se desenrola de forma precária e sem perspectivas de finalização, a área vem sofrendo prejuízos ambientais, tendo em vista que não existe proteção e nem diretrizes para a sua conservação. Um dos segmentos econômicos que mais tem prosperado na região é o Ecoturismo, que é uma eficaz ferramenta para a educação ambiental, contribui para a conservação do patrimônio ambiental e cultural das localidades, pois o meio ambiente preservado passa a ser entendido como a fonte de renda para as comunidades locais. O objetivo do trabalho foi criar e adequar nesta área uma rota ecoturística de trekking para envolver os empreendimentos turísticos existentes, ligando-os através de um caminho ecológico composto por trilhas, na área ainda não regularizada do Parque Nacional da Serra da Canastra no município de São João Batista do Glória-MG. Para isso, foram percorridos os caminhos já existentes, mapeando as trilhas já abertas que poderiam ser utilizadas; apresentando os tempos necessários de cada percurso divididos por trechos; as severidades das condições dos terrenos visando implantar a Norma Técnica ABNT NBR 15505-2: Turismo com atividades de caminhada; norma esta sugerida pelo Ministério do Turismo e Associação Brasileira de Empresas de Turismo de Aventura - ABETA. A criação e a classificação da rota de trekking e a disponibilização dos dados de GPS proporciona segurança para quem pretende se aventurar nas trilhas e tende a impulsionar o turismo, inserindo o pólo ecoturístico de São João Batista do Glória no roll de destinos turísticos providos de trilhas adequadas ao trekking. Outro benefício será o aumento da demanda por guias de turismo locais, profissionalizando o turismo na região de estudo. Os resultados serão decisivos para a adequação do produto turístico, gerando qualidade da visitação, maior facilidade na comercialização dos roteiros, culminando em mais desenvolvimento econômico e sustentável para a região.

PALAVRAS-CHAVE: Cerrado; Ecoturismo; NBR 15505-2; Parque Nacional da Serra da Canastra; Trekking. 


\section{ABSTRACT}

The Brazilian Cerrado is the second largest biome in Brazil, and spreads over eight different States, which plays a crucial role in the issue of water resources. The object of study is the remainder area of 200,000 hectares of Cerrado biome in the National Park of Serra da Canastra, a zone that has been under land disputes since 1972 as a result of the Brazilian Government's inefficiency to implement a conservation unit covering the whole area. While this situation persists with no solution in sight, the area suffers environmental damage aggravated by the absence of protective measures and guidelines for conservation. Ecotourism is one of the most successful business activities carried out in the region and can function as an effective tool for environmental education and conservation of local natural resources and cultural heritage. It enables local communities to benefit financially from preserved natural resources, providing incentives for conservation. The objective is to create and tailor this area an ecotourism hiking trails to engage existing ecotourism businesses by linking them through an ecological path composed of trails in the area have not regularized in the Serra da Canastra National Park in São João Batista do Glória -MG. To this, they were covered existing paths, since mapping the open tracks that could be used; presenting the necessary times for each route divided into sections; the severities of the land conditions in order to implement the Technical Standard NBR 15505-2 Holidays with hiking activities; this standard suggested by the Ministry of Tourism and the Brazilian Association of Adventure Tourism Companies - ABETA. The creation and classification of the hiking trails and the availability of GPS data provides security for those who want to venture out on the trails and tends to boost tourism by entering the ecotourism hub of São João Batista do Glória in the roll of tourist destinations provided tracks suitable for hiking. Another benefit is the increased demand for local tour guides, more professional and aware tourism in the study area. The results will be decisive for the adequacy of the tourism product, generating quality visitors, greater ease in marketing scripts, resulting in more economic development to the region, sustainably.

KEYWORDS: Cerrado; Ecotourism; NBR 15505-2; Serra da Canastra National Park; Hiking.

\section{Introdução}

Os parques nacionais inicialmente concebidos para proteger a monumentalidade da natureza, originalmente implantados nos EUA e Europa, foram exportados para o resto do mundo como instrumentos legítimos de ordenamento das relações entre o meio natural e as populações tradicionais que o habitam (SPINOLA, 2013).

A conservação e manutenção das áreas naturais remanescentes no Brasil é um grande desafio. O país que se destaca por sua enorme área e abriga dois biomas morfoclimáticos no mapa dos Hotspots biodiversidade mundial, o Cerrado e a Mata Atlântica. Os hotspots são pontos no Planeta Terra que se caracterizam pela enorme diversidade biológica, além de alto endemismo de espécies. Este conceito veio para auxiliar os conservacionistas a identificar as áreas mais importantes para a preservação das espécies e fornecer a base científica ao direcionamento de pesquisas e estratégias de conservação (MITTERMEIER, 1999 apud CASTRO, 2013).

A economia do município de São João Batista do Glória, situado no Sudoeste do Estado de Minas Gerais sempre foi baseada na agropecuária, o que causa uma grande dependência do setor, no entanto, o turismo vem se despontando como um setor importante economicamente. O município tem em sua área relevantes aspectos de riqueza natural e cultural, que precisam ser preservados e melhor 
aproveitados. Um dos inúmeros fatores que motivaram este trabalho é potencial de desenvolvimento sustentável e econômico que o segmento do ecoturismo possui.

Grande parte da área do Município em estudo é composta por Cerrado, localizado em uma região de transição geológica, e que abriga um dos poucos Parques Nacionais Brasileiros criados para a conservação deste bioma, o Parque Nacional da Serra da Canastra (PNSC).

O Parque ainda se encontra em processo de regularização fundiária, e quando se efetivar a sua ampliação e formalização, do total da área do Município, $46,51 \%$ será composto pelo Parque. Esta influência se amplia ao considerar a Zona de Amortecimento deste Parque, área esta que precisa ser trabalhada de forma equilibrada, mediante ações de planejamento para o estímulo de seu potencial ecoturístico (ICMBio, 2005).

De acordo com o Decreto no 70.355, em 3 de abril de 1972, o Parque foi oficialmente criado com uma área de $197.787,00$ ha. Destes, $71.525,00$ ha estão regularizados, o denominado Chapadão da Canastra, onde está localizado a Nascente histórica do Rio São Francisco e a Cachoeira Casca d'Anta. Enquanto que nos 126.262,00 ha restantes, que perfazem o berço das águas do Rio São Francisco, ainda se encontram sem definição, sob propriedades privadas, sendo eles a Serra da Gurita, Serra da Bateia, Vão dos Cândidos, Serra da Babilônia e o Vale dos Canteiros até os Chapadões de Furnas (ICMBio, 2005).

Esse trabalho constitui-se em um ensaio prático que pretende suavizar a relação conflituosa que se estabeleceu entre os objetivos da conservação da natureza e da inserção econômico social de uma parte da região não regularizada do Parque Nacional da Serra da Canastra. No entanto o objetivo principal deste trabalho é o desenvolvimento local através do planejamento e a criação de uma rota ecoturística de trekking para envolver os empreendimentos turísticos, entre eles Pousadas, Campings e Restaurantes, ligando-os por meio de um caminho ecológico composto por trilhas, dotando a região de um produto turístico bem formatado e de visibilidade que possa gerar renda e manter uma relação sustentável entre o homem do campo e a natureza.

\section{A caminhada}

Segundo Camargo e Bernardes (2010), a caminhada é um dos exercícios mais práticos, democráticos e acessíveis que existe. As contraindicações são difíceis de serem encontradas, já que é um movimento natural do ser humano. É um dos exercícios mais praticados devido à facilidade de execução e simplicidade.

Existem diversas palavras que classificam os diferentes tipos de caminhadas, que podem ser segundo sua duração ou envolvimento com 0 ambiente. Em parte as definições vieram do inglês e foram traduzidas para 0 português. A principal e mais difundida das modalidades é o Trekking (CAMARGO; BERNARDES, 2010).

Na definição de Penteado (1994), o Trekking pode ser entendido como uma atividade esportiva, uma caminhada rústica por trilhas com orientação por meio de mapas, bússola ou GPS, em ambientes naturais como florestas, montanhas, cerrados, rios, trilhas e áreas com acidentes causados pela própria natureza. Geralmente é praticado em grupo, estimulando o espírito de companheirismo e 
promovendo a interação com a natureza, muitas vezes movida pela emoção e pelo espírito aventureiro.

Assim, considerando a dimensão dos riscos dos outros esportes de turismo de aventura, vale apontar, que, no trekking, o risco/perigo, a aventura e a emoção/adrenalina encontram-se minimizados. Existe um nítido contraste, no discurso sobre as atividades oferecidas pelas operadoras de turismo de aventura, onde as atividades de trekking estão pouco relacionadas às questões de segurança e enfatizam mais o contato com o meio ambiente e a beleza do cenário (SPINK et al. 2005).

\section{Potencial brasileiro}

O Brasil possui um potencial incrível para se desenvolver neste segmento. Segundo Menezes (2014) nos 75 milhões de hectares do Sistema Federal de Unidades de Conservação Brasileiro existem menos de $300 \mathrm{~km}$ de trilhas classificadas e sinalizadas.

Nesse sentido, o incentivo à visitação nos parques nacionais brasileiros deve ser sempre estimulada, uma vez que a manutenção de parques fechados ou mesmo sem condições mínimas para recepção de visitantes é impeditivo à proteção de seus ecossistemas e ao desenvolvimento sociocultural da região em que estão inseridos (CAVALCANTI; PIRES, 2015).

Os caminhos brasileiros de trekking, em sua maioria, são réplicas do Caminho de Santiago de Compostela e não estão inseridos em Unidades de Conservação, como por exemplo, os Parques Nacionais.

O Caminho de Santiago de Compostela é uma das rotas de peregrinação e trekking mais conhecidas e realizadas no mundo (PEAKE, 1919 apud MENDES, 2009). Atrai, anualmente, um número significativo de pessoas de diferentes nacionalidades, que iniciam as peregrinações em diversos locais ao longo da Península Ibérica, distribuídas em nove rotas distintas (CARNEIRO, 2001).

Após grande exposição e difusão pelo mundo inteiro, o Caminho de Santiago de Compostela tornou-se modelo ideal de caminhadas de longo percurso, fazendo com que idealizadores reproduzissem essas peregrinações em terras brasileiras, seja para reviver as experiências ou mesmo como treinamento para sua posterior realização. Algumas rotas se destacam no cenário Nacional, que ainda é muito pouco considerado neste segmento.

Segundo Steil e Carneiro (2008) as principais rotas brasileiras de trekking, seguindo o modelo espanhol, são: O Caminho do Sol, que se inicia em Santana do Parnaíba-SP e termina em Águas de São Pedro-SP, com extensão total de $240 \mathrm{~km}$. O Caminho da Fé com $497 \mathrm{~km}$, tem Início em Águas da Prata-SP e termina em Aparecida do Norte-SP. E o Caminho da Luz que tem Início em Tombos-MG, terminando no Pico da Bandeira com extensão de 200 km.

\section{Localização da área de estudo}

A área de estudo é a porção do Parque Nacional da Serra da Canastra que está inserida dentro dos limites municipais de São João Batista do Glória-MG, perfazendo $46,51 \%$ do total da área do Município (Figura 1). 

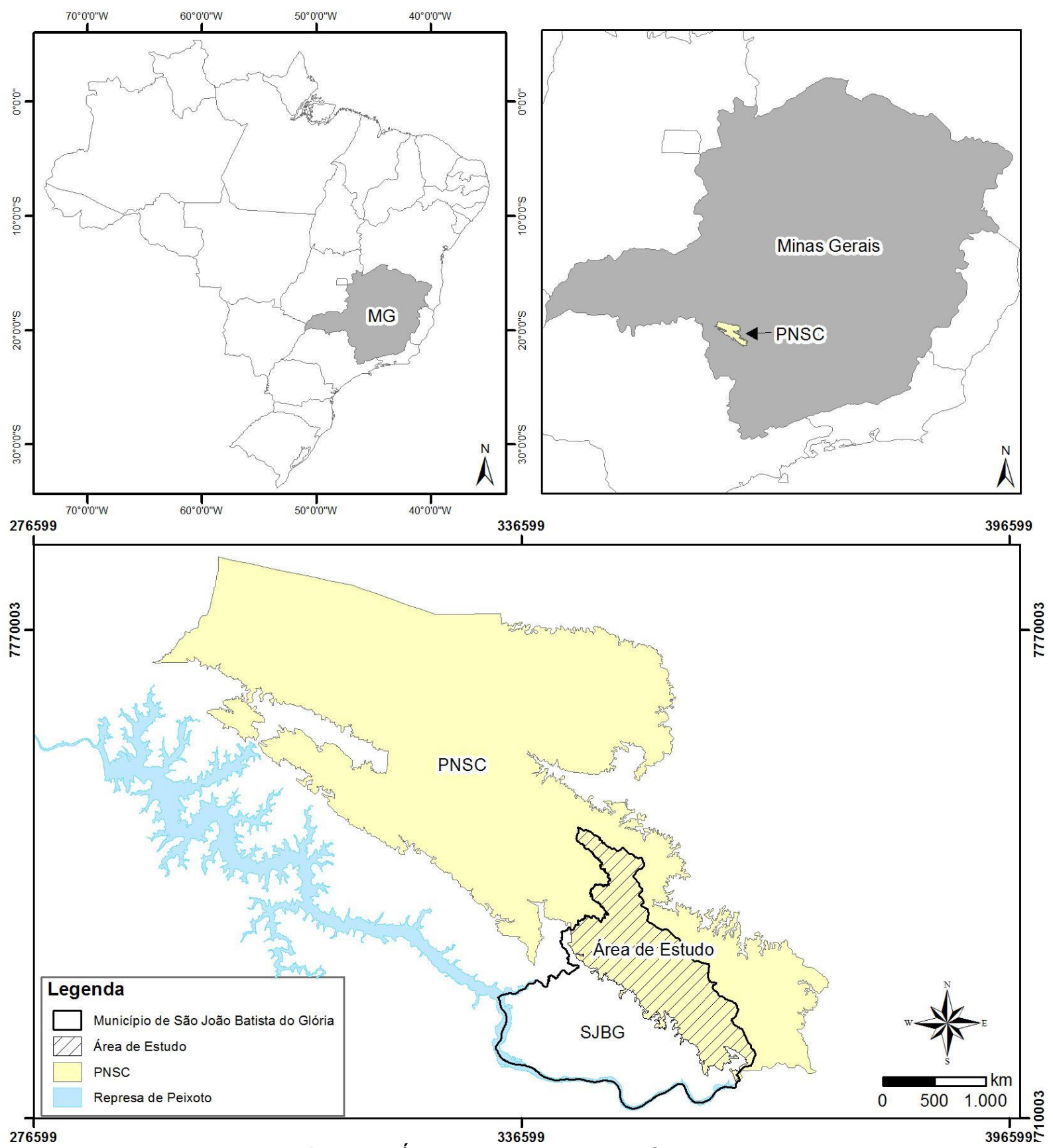

Figura 1: Área de Estudo. Fonte: Os autores.

Figure 1: Study Area. Source: The Authors.

\section{As travessias}

As caminhadas de longo percurso, conhecidas também como travessias, são caminhadas em ambientes naturais, preferencialmente em Unidades de Conservação (UC). Envolvem pernoite, uso de equipamentos específicos e também a presença de um condutor com algumas competências. $O$ condutor, é 0 profissional que recepciona, orienta, prepara e conduz o caminhante ou o grupo de caminhantes, de forma segura, nas atividades de caminhada - ABNT NBR 15398. Envolve planejamento de estratégias e logística, preparação de equipamentos além da superação de obstáculos durante a caminhada em si (REBELLO, 2012). 
O consumo destes produtos de ecoturismo e turismo de aventura, segundo Gouveia et al. (2014) está intimamente relacionado com duas categorias motivacionais: as físicas (atividades, como esportes, que reduzem a tensão e promovem o relaxamento) e as culturais (desejo de explorar outras culturas e busca por novas experiências).

No Brasil, as travessias vêm se desenvolvendo e destacam-se a Serra dos Órgãos com a travessia Petrópolis/Teresópolis; a Chapada Diamantina com a travessia Vale do Pati; a Serra da Mantiqueira com as travessias no interior do Parque Nacional de Itatiaia e ao longo da Serra Fina e o Parque Estadual da Serra Geral do Intendente em Minas Gerais com a travessia Lapinha/Tabuleiro (ABETA, 2009).

Uma iniciativa de vanguarda dentro do ICMbio está em curso. Foi inaugurada em 10/10/2015 o programa travessias do Parque Nacional da Serra do Cipó, que é uma trilha de $65 \mathrm{~km}$ que cruza toda a extensão do Parque. O projeto começou a ser articulado em 2014 com a supervisão do Conselho Consultivo do Parque que aprovou uma resolução que estabelecia a criação de uma trilha conforme plano de manejo (ICMbio, 2015).

\section{Certificação das atividades}

A certificação do turismo de aventura no Brasil constitui-se em um processo em franca evolução, e, para garantir a credibilidade e garantir as diretrizes exige a participação dos órgãos públicos e privados para seu desenvolvimento. Assim, em 2003, o Governo brasileiro, por meio do Ministério do Turismo e a Associação Brasileira de Normas Técnicas - ABNT, por meio do seu Comitê Brasileiro do Turismo (ABNT/CB-54) viabilizou um projeto que criou 24 Normas Técnicas específicas para atividades de turismo de aventura, visando a operação segura e responsável. Estas normas são utilizadas como instrumento de certificação da conformidade de pessoas e organizações (OLIVEIRA; COVALAN, 2008).

As normas criadas vêm sendo implementadas e coordenadas pela Associação Brasileira das Empresas de Turismo de Aventura - ABETA e tanto podem ser aplicadas em produtos, serviços, processos, sistemas de gestão ou pessoas, estabelecimento de requisitos de qualidade, desempenho, segurança, como fornecer procedimentos, formas ou dimensões, classificações, terminologias, medição ou determinação de características (UVINHA, 2005 apud OLIVEIRA; COVALAN, 2008).

Nesta etapa do processo de certificação são abordados assuntos como competências mínimas para condutores das diversas atividades, especificações dos produtos utilizados nessas atividades, gestão da segurança e informações mínimas que o cliente deve receber antes de iniciar a prática de uma atividade de turismo de aventura (MTUR, 2005). Entretanto, deve-se frisar que o processo de certificação do turismo de aventura no Brasil ainda é voluntário, ou seja, ainda é exercido sem certificação apesar dos riscos e perigos envolvidos no seu desenvolvimento. 


\section{As normas da ABNT}

Nos últimos anos o Turismo de Natureza brasileiro tem sido estrategicamente pensado para atingir níveis de qualidade internacionais, espelhado em países com reconhecida atuação e tradição no segmento de turismo na natureza. A ABETA sistematicamente tem incentivado os proprietários de atrativos turísticos que atuam no segmento de natureza a se capacitarem e a seus colaboradores, através do Programa Aventura Segura (PAS) em parceria com o Ministério do Turismo (MTUR) e a Associação Brasileira de Normas Técnicas (ABNT) e os resultados apontam para avanços significativos no segmento de natureza, em especial, nas atividades e tipologias ligadas a aventura (EICHENBERG; SILVA, 2013).

As normas da ABNT especificam requisitos para a certificação de pessoas e produtos, considerando o objetivo e campo de aplicação, onde é apresentada a finalidade de uso da norma; as referências normativas, ou seja, a lista das referências de normas indispensáveis na aplicação da norma; os termos e definições, onde estão incluídos os termos e definições necessários ao perfeito entendimento e utilização da norma, e os requisitos descritos para o estabelecimento de políticas e procedimentos, estrutura organizacional, diretrizes para o desenvolvimento e manutenção de um esquema de certificação e toda informação das atividades e itens associados (SOUZA et al., 2008).

\section{Procedimentos metodológicos}

Para criar a rota, inicialmente denominada Caminhos da Canastra, foi feita uma pesquisa de gabinete sobre o município de São João Batista do Glória, que fica no extremo sul da área do Parque. Os aspectos fisiográficos foram levantados, arquivos de trakmaker existentes foram pré-selecionados, visando diagnosticar a existência das estradas e trilhas mapeadas do município. As trilhas já existentes na área em estudo foram criadas por intenso movimento de motos e jipes, geralmente em trilhas antigas criadas por mineradoras, ou seja, sem fundamentação técnica ou normativa. Para compilar os dados foram utilizadas técnicas de geoprocessamento e sensoriamento remoto, através do software ArcGis e também o suporte do Google Earth onde foram demarcados os pontos relevantes como pousadas, bifurcações e entroncamentos, acidentes naturais relevantes, construções, pedreiras abandonadas, rios e riachos, declividade acentuada, entre outros, visando definir e otimizar o melhor traçado.

Para compor o documento base do trabalho foram utilizadas imagens de satélite RapidEye, com resolução espacial de $5 \mathrm{~m}$. Estas imagens se apresentam georreferenciadas no Datum WGS84 e foram cedidas pelo Ministério do Meio Ambiente a um dos membros da Equipe Executora deste projeto. A delimitação dos municípios e da rede hidrográfica foram obtidas no sítio digital do Instituto Brasileiro de Geografia e Estatística -IBGE; a delimitação do Parque Nacional e sua área regularizada e não regularizada foram obtidas no sítio digital do ICMBio. O mapa com as altitudes, utilizado para compor os painéis interpretativos, foi obtido do trabalho de Magri (2013).

O segundo passo foi verificar e vivenciar em campo o cenário levantado, os possíveis pontos de dificuldade, adversidades e viabilidade do traçado. Com o uso de GPS Garmin, foram percorridos e mapeados todos os trechos dos trajetos 
pesquisados em gabinete, pontualizando e fotografando pontos do percurso, como por exemplo, pontos íngremes, locais alagadiços, pisos escorregadios, além de confirmar sentidos em bifurcações e entroncamentos, pontos de água potável, pontos de apoio com sombras e mirantes. Foram realizadas seis visitas a campo para a conferência e obtenção de dados, todas elas previamente planejadas com a notificação das pousadas, que disponibilizaram apoio logístico como pernoite e disponibilização de cavalos para carregar equipamentos.

Após a obtenção dos dados em campo, foram confrontados os trajetos e delimitado o eixo principal da trilha, perfazendo um total de $37 \mathrm{~km}$ divididos em três percursos. Para consolidar e aprovar a rota, foram realizados três eventos testes para confirmar e aplicar a atividade. Durante os eventos houve o monitoramento das pessoas para diagnosticar a viabilidade e o interesse destas. Envolveu 49 turistas que realizaram os três percursos, em dias alternados, como forma de confirmar os níveis de dificuldade e aprovar a viabilidade da rota Caminhos da Canastra.

\section{A seleção dos percursos}

A seleção dos percursos foi um processo que demandou conhecimento prévio do terreno, envolvimento com a comunidade e também a preocupação com a segurança, onde foi necessário o estabelecimento de trajetos compatíveis e concisos com a prática do trekking.

Para aumentar a segurança na atividade e gerar informações prévias e confiantes para clientes, para prestadores de serviços e operadoras turísticas, aplicou-se a norma da ABNT NBR 15505-2 Turismo com Atividades de Caminhada Parte 2: Classificação de percursos, que por sua vez utilizou como referência o chamado Método de Informaccion de Excursiones (M.I.D.E.), da Federación Aragonesa de Montañismo (FEMDE), da Espanha.

Esta norma se aplica a caminhadas que podem posteriormente serem oferecidas como produto turístico. A Norma ABNT NBR 15505-1 Turismo com atividades de caminhada Parte 1: Requisitos para Produto direciona empresas de turismo interessadas em operacionalizar e comercializar os percursos classificados.

Os percursos (P1, P2, P3) criados e classificados foram efetuados para a atividade específica de caminhada e foram nomeados e separados (Quadro 1).

Quadro 1: Nomenclatura dos Percursos e Trechos da Rota.

Table 1: Naming of routes.

\begin{tabular}{|c|c|c|c|c|c|}
\hline $\mathbf{P} 1$ & Furnas - Canteiros & $\mathbf{P} 2$ & Canteiros - Letreiros & P 3 & Letreiros - Quilombo \\
\hline \multirow{4}{*}{ 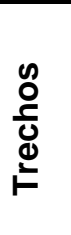 } & Curral & \multirow{4}{*}{ 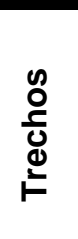 } & Cotovelo & \multirow{4}{*}{ 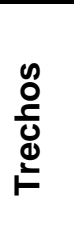 } & Rasga Saco \\
\hline & Muro de Pedra & & Buraco da Nega & & Tia Ciça \\
\hline & \multirow{2}{*}{ Terras Férteis } & & Garrida & & \multirow{2}{*}{ Quilombo } \\
\hline & & & Mirante & & \\
\hline
\end{tabular}

Fonte: Os autores.

Source: The authors. 
Após definidos e nomeados os trechos da rota Caminhos da Canastra, utilizou-se as referências de classificação de percurso da Norma ABNT NBR 155052 para obtenção dos resultados.

\section{Critérios de classificação}

A classificação dos percursos seguiu os quatro critérios da norma ABNT NBR 15505-2, que seguem abaixo:

- Severidade do meio: refere-se aos perigos e outras dificuldades decorrentes do meio natural, como temperatura, pluviosidade, riscos de quedas, dificuldade de resgate, entre outros, que podem ser encontrados ao longo do percurso;

- Orientação no percurso: refere-se ao grau de dificuldade para orientação, como presença de sinalização, trilhas bem marcadas, presença de pontos de referência, entre outros, para completar o percurso;

- Condições do terreno: refere-se aos aspectos encontrados no percurso em relação ao piso e às condições para percorrê-lo, como tipos de pisos, trechos com obstáculos, trechos com pedras soltas, entre outros;

- Intensidade de esforço físico: refere-se à quantidade de esforço físico requerido para cumprir o percurso, levando em conta extensão e desníveis (subidas e descidas), considerando uma pessoa comum.

Considera-se pessoa comum uma pessoa adulta, não esportista e com bagagem leve (utensílios básicos). A classificação de um percurso pode variar de acordo com a variação das condições de cada estação do ano.

\section{Procedimentos de classificação}

O percurso classificado foi dividido em trechos para avaliar cada critério. Os trechos são partes do percurso com características distintas, e que juntos compõem a classificação do percurso.

Cada trecho foi avaliado para cada um dos critérios. A cada critério foi atribuído um valor em uma escala de 1 a 5 . Todos os percursos foram classificados utilizando-se os quatro critérios.

\section{Severidade do meio}

A classificação para este critério foi efetuada contando-se o número de ocorrências de fatores de forma cumulativa. Os fatores são definidos na norma ABNT 1550502 e variam desde a presença de água potável no trecho até desprendimento involuntário de rochas no percurso. Durante a classificação cada fator foi contado somente uma vez, independentemente de sua probabilidade de incidência. $A$ classificação utilizada para determinar a severidade do meio em função do número de fatores identificados para cada trecho (Tabela 1). 
Tabela 1: Classificação segundo a severidade do meio.

Table 1: Classification of the severity of the environment.

\section{Critério de percurso}

Classificação

Número de Fatores

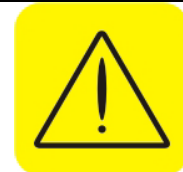

Severidade do Meio

\begin{tabular}{|c|l|c}
\hline $\mathbf{1}$ & Pouco Severo & Até 3 \\
\hline $\mathbf{2}$ & Moderadamente Severo & $\mathbf{4}$ ou 5 \\
\hline $\mathbf{3}$ & Severo & 6 a 8 \\
\hline $\mathbf{4}$ & Bastante Severo & 9 a 12 \\
\hline $\mathbf{5}$ & Muito Severo & Pelo menos 13 \\
\hline
\end{tabular}

Fonte: Adaptado da Norma ABNT NBR 15505-02.

Source: Adapted from Standard ABNT NBR 15505-02.

\section{Orientação no percurso}

A classificação para este critério foi efetuada avaliando-se as condições do itinerário (Tabela 2). Cada trecho foi avaliado em relação à facilidade de orientação para percorrê-lo. As condições definidas na norma ABNT 15505-02 são distintas e variam entre o esforço de identificação do traçado, passando pela necessidade de identificação de acidentes geográficos, até avaliações das interseções e cruzamentos diversos no caminho.

Tabela 2: Classificação segundo a orientação no percurso.

Table 2: Classification of guidance along the way

\section{Critério de percurso}

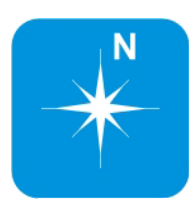

Orientação no percurso

\section{Classificação}

\begin{tabular}{|c|c|}
\hline 1 & Caminhos e cruzamentos bem definidos \\
\hline 2 & Caminho ou sinalização que indica a continuidade \\
\hline 3 & $\begin{array}{l}\text { Exige a identificação de acidentes geográficos e de } \\
\text { pontos cardeais }\end{array}$ \\
\hline 4 & Exige habilidades de navegação fora do traçado \\
\hline 5 & $\begin{array}{l}\text { Exige navegação para utilizar trajetos alternativos e não } \\
\text { conhecidos previamente }\end{array}$ \\
\hline
\end{tabular}

Fonte: Adaptado da Norma ABNT 15505-02.

Source: Adapted from Standard ABNT NBR 15505-02

\section{Condições do terreno}

A classificação para este critério foi efetuada contabilizando fatores ambientais e analisando as condições do terreno. Cada trecho foi percorrido e avaliado em relação à dificuldade, analisando às condições do terreno, obstáculos e adversidades. Os fatores observados nas trilhas seguiram as normas, e são estradas vicinais utilizadas por veículos automotores, regularidade do piso, inclinações, obstáculos que podem exigir saltos ou a utilização das mãos até trechos que exigem técnicas de escalada. Os níveis do critério supracitado são apresentados (Tabela 3). 
Tabela 3: Classificação segundo condições do terreno.

Table 3: Classification according to ground conditions.

\begin{tabular}{|c|c|c|}
\hline Critério de percurso & \multicolumn{2}{|r|}{ Classificação } \\
\hline & 1 & Percurso em superfícies planas \\
\hline & 2 & Percurso por caminhos sem obstáculos \\
\hline & 3 & Percurso por trilhas escalonadas ou terrenos irregulares \\
\hline & 4 & Percurso com obstáculos \\
\hline $\begin{array}{l}\text { Condições do } \\
\text { terreno }\end{array}$ & 5 & Percurso que requer técnicas verticais \\
\hline
\end{tabular}

Fonte: Adaptado da Norma ABNT 15505-02.

Source: Adapted from Standard ABNT NBR 15505-02

\section{Intensidade de esforço físico}

Um dos critérios mais importantes e indispensáveis é o esforço físico. Cada trecho foi avaliado em relação à estimativa do esforço necessário, levando em conta a distância a ser percorrida e a influência dos desníveis (subidas e descidas). $O$ índice de esforço para caminhada em percursos de turismo da Norma ABNT 15505-02 é expresso em horas e considera-se o praticante uma pessoa adulta, não esportista e com bagagem leve.

O índice foi calculado, para trechos horizontais, a partir do cálculo do tempo de deslocamento horizontal obtido, dividindo-se a distância percorrida por uma velocidade média na horizontal conforme a equação abaixo:

\section{$T h=(D p) / V h$}

Onde Th: é o tempo de deslocamento na horizontal, $D p$ : é a distância percorrida no trecho e $V h$ : é a velocidade média na horizontal. As velocidades médias na horizontal a utilizar nesse cálculo estão apresentadas abaixo:

- $\quad$ Piso Fácil (estradas e pistas): $4 \mathrm{~km} / \mathrm{h}$

- $\quad$ Piso Moderado (trilhas, caminhos lisos e prados): $3 \mathrm{~km} / \mathrm{h}$

- Piso Difícil (caminhos ruins, pedregosos, leitos de rios): $2 \mathrm{~km} / \mathrm{h}$

A influência do desnível é levada em conta calculando-se o tempo adicional devido aos desníveis (subidas ou descidas). Esse tempo representa um esforço adicional. É calculado utilizando-se o desnível dividido por uma velocidade vertical padrão, de acordo com o tipo de piso do trecho. Esses tempos adicionais para cada trecho devem ser calculados usando as equações abaixo:

\section{Ts=D/Vs TD=D/VD}

Onde $D$ é o desnível; $V s$ é a velocidade de deslocamento vertical em aclive; $V d$ é a velocidade de deslocamento vertical em declive; Ts é o tempo na subida e Td é o tempo na descida. 
Em cada trecho, foi calculado o acréscimo correspondente às subidas, independentemente do acréscimo correspondente às descidas. $O$ tempo correspondente aos desníveis é a soma do tempo correspondente às subidas com 0 correspondente às descidas.

Para o cálculo de acréscimos de tempo para trechos com desnível, considerou-se o tipo de inclinação, aclive (subida) ou declive (descida), padronizando a velocidade média da caminhada para cada um em $200 \mathrm{~m} / \mathrm{h}$ para aclive e em $300 \mathrm{~m} / \mathrm{h}$ para declive.

Em cada trecho calculou-se dois tempos: o tempo correspondente ao deslocamento na horizontal e o tempo correspondente aos desníveis.

Para a análise do percurso foram somados os tempos correspondentes a cada trecho, resultando um tempo total para o deslocamento na horizontal e outro tempo total para os desníveis.

O índice de esforço para caminhada em percursos de turismo é o resultado da soma do maior tempo obtido com a metade do menor tempo obtido. Lembrando que a Norma ABNT 15505-02 rege estes cálculos.

$$
\text { IE }=T_{\text {MAIOR }}+\left(T_{\text {MENOR/2 }}\right)
$$

Onde IE é o índice de esforço para caminhada em percursos de turismo e T é o tempo, expresso em horas (h).

A classificação para este critério foi efetuada estimando-se o esforço físico necessário para completar o percurso, em termos de duração da atividade, segundo Normas da ABNT 15505-02 (Tabela 4).

Tabela 4: Índice de esforço para caminhada em percursos de turismo.

Table 4: Classification of the effort index for walking tourism routes.

\begin{tabular}{|c|c|c|c|}
\hline Critério de percurso & & Classificação & Estimativa de duração (h) \\
\hline \multirow{5}{*}{$\begin{array}{l}\text { Intensidade } \\
\text { de esforço } \\
\text { físico }\end{array}$} & 1 & Pouco esforço & Até 1 \\
\hline & 2 & Esforço moderado & Mais de 1 e até 3 \\
\hline & 3 & Esforço significativo & Mais de 3 e até 6 \\
\hline & 4 & Esforço intenso & Mais de 6 e até 10 \\
\hline & 5 & Esforço extraordinário & Mais de 10 \\
\hline
\end{tabular}

Fonte: Adaptado da Norma ABNT 15505-02.

Source: Adapted from Standard ABNT NBR 15505-02.

\section{Comunicação da classificação}

Após a obtenção dos resultados procedeu-se a elaboração dos painéis de comunicação da classificação do percurso, que expressam o nível de exigências técnicas e físicas. Elas foram esboçadas baseando-se nos quatro critérios estudados de forma unificada, com o resultado de cada critério associado ao símbolo respectivo. Na tabela de comunicação deve constar as seguintes informações: 
- Local de início e local de chegada

- Desnível total de subida;

- Desnível total de descida;

- Distância total;

- Condições específicas relevantes (como, por exemplo, percursos autoguiados, chuvas, época do ano, áreas alagadas, entre outros).

Ressalta-se os painéis de comunicação deverão estar implantados nas pousadas que perfazem a rota, além de constar o croqui da trilha para melhor compreensão.

\section{Os percursos}

\section{Travessia Furnas - Canteiros}

Interpretando e analisando as informações, chegou-se aos fatores de cada critério, que foram descritos para posteriormente serem repassados para os painéis de comunicação das exigências técnicas e físicas dos percursos, que serão inseridos nas pousadas e pontos de início da rota. Foi criado um bureau de comunicação para divulgação mais detalhada ao ecoturista (Anexo 1).

No critério Severidade do Meio, o trecho Curral foi classificado como moderadamente severo e os trechos Muro de Pedra e Terras Férteis foram classificados como moderadamente severo. Assim, o resultado final do percurso foi moderadamente severo (Tabela 1).

Avaliando o critério Orientação de Percurso, nos trechos Curral e Terras Férteis o resultado parcial obtido é Caminho que indica a continuidade, por haver estradas vicinais e caminhos bem marcados. No trecho Muro de Pedra, foi diagnosticada a exigência de identificação de acidentes geográficos e ou pontos cardeais, por existir trechos onde a trilha não é bem marcada, com a presença de grandes campos limpos de Cerrado, o que dificulta a orientação na trilha, fazendo com que a Travessia Furnas-Canteiros seja classificada como Exigência de identificação de acidentes geográficos e ou pontos cardeais, ou seja, é necessário a presença de guia de turismo no trajeto.

No critério Condições do Terreno, (Tabela 3), cada trecho obteve uma classificação distinta, sendo o trecho Curral diagnosticado como superfícies planas, pois concentra estradas vicinais. $O$ trecho Muro de Pedra resultou como percurso por trilhas escalonadas ou terrenos irregulares, pois há a necessidade de cruzar pequenos riachos, áreas alagadiças e trilhas que exigem calçamento adequado e condizente ao piso irregular. O trecho Terras Férteis, foi classificado como sendo trecho por caminhos sem obstáculos, com uma observação para a presença de colchetes nas cercas das pequenas fazendas. Assim, o resultado final do critério condições do terreno, foi classificado como Percurso por trilhas escalonadas ou terrenos irregulares.

Para finalizar o percurso inicial, e analisar o critério Intensidade do Esforço Físico, calculou-se separadamente cada trecho obtendo dois números por trecho, sendo eles, o tempo de caminhada na horizontal e a somatória dos tempos de caminhada em locais íngremes ou com declives. O cálculo dos três trechos do percurso, Curral, Muro de Pedra e Terras Férteis, após a somatória, resultou no 
índice de 6,75 que, transformado em horas, chega-se ao tempo de 6:45h, que se refere ao tempo total do percurso, incluindo o tempo das paradas para descanso e lanche, a influência das variações altimétricas e a velocidade empregada.

Assim, a Travessia Furnas-Canteiros foi classificada como sendo uma caminhada de Esforço Intenso, (Tabela 4).

O resultado da aplicação da norma ABNT NBR 15505-02 são comunicados como segue (Quadro 2).

Quadro 2: Painel interpretativo.

Table 2 : interpretive panel.

\begin{tabular}{|c|c|c|c|}
\hline \multicolumn{2}{|c|}{ Travessia Furnas - Canteiros } & \multicolumn{2}{c|}{$\begin{array}{c}\text { CAMINHOS DA CANASTRA } \\
\text { MINAS GERAIS - BRASIL }\end{array}$} \\
\hline Atividade: Caminhada - Trekking & \multicolumn{2}{|c|}{ Tempo Médio de Percurso: 6h e 45mi8n } \\
\hline Trajeto: Paraiso Perdido (Altitude: $817 \mathrm{~m}$ ) até a Pousada Canteiros (Altitude: $1055 \mathrm{~m}$ )
\end{tabular}

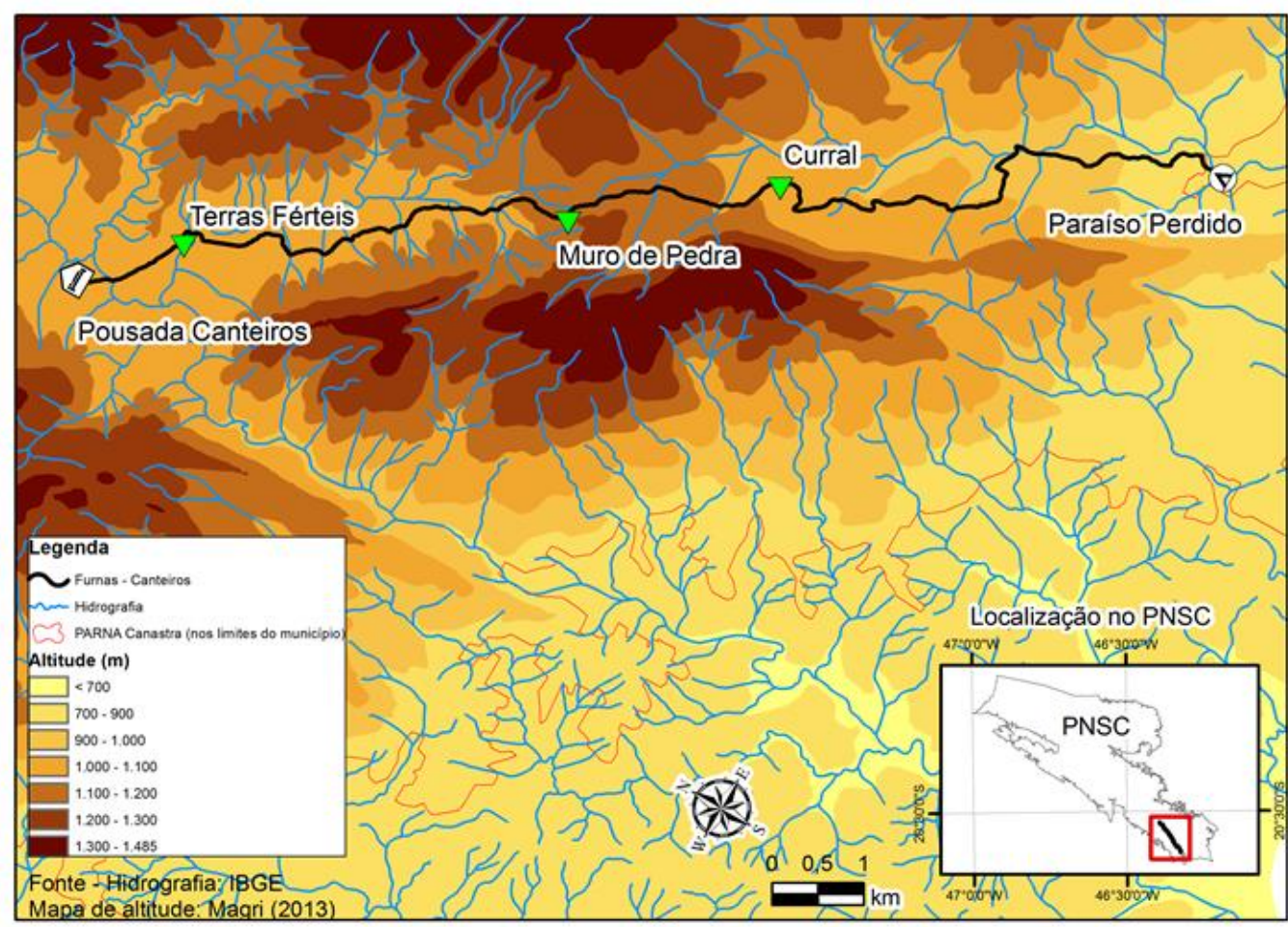




\section{Travessia Canteiros - Letreiros}

Por duas vezes durante as pesquisas de campo, percorreu-se a totalidade do percurso para obter os dados técnicos, que foram compilados para posteriormente serem calculados.

Interpretando e analisando as informações obtidas, procedeu-se seleção dos fatores e no cálculo das variantes dos critérios, que foram transcritos abaixo, para posteriormente serem repassados para o painel final de comunicação das exigências técnicas e físicas dos percursos. Foi criado um bureau de comunicação para divulgação mais detalhada ao ecoturista (Anexo 2).

No critério Severidade do Meio, o trecho Cotovelo foi classificado como Pouco Severo; o trecho sequente, Buraco da Nega com muitas áreas de mineração abandonadas e trilhas com pedras soltas foi classificado como Severo; o trecho Garrida foi classificado como Moderadamente Severo; e o último trecho do percurso, Mirante, como Pouco Severo. Assim, o resultando do percurso Travessia Canteiros-Letreiros foi Severo (Tabela 1).

Avaliando o critério Orientação de Percurso, os trechos Cotovelo e Mirante o resultado parcial obtido é Caminho e Cruzamentos bem definidos, por haver estradas vicinais e caminhos bem marcados. O trecho Buraco da Nega foi diagnosticado com exigência de identificação de acidentes geográficos e ou pontos cardeais, por existir trechos onde a trilha não é bem marcada, com a presença de grandes campos rupestres de Cerrado, o que dificulta a orientação na trilha. Já o trecho Garrida, que é uma antiga trilha de caminhões de mineradoras de quartzito, foi classificada como Caminho que indica a continuidade. Deste modo, a Travessia Canteiros-Letreiros no quesito Orientação de Percurso, foi classificada como Exigência de Identificação de Acidentes Geográficos e ou Pontos Cardeais, ou seja, é necessário a presença de guia de turismo no trajeto (Tabela 2).

Já no critério Condições do Terreno os trechos Cotovelo e Mirante foram diagnosticados como Superfícies Planas, pois concentra estradas vicinais; o trecho Buraco da Negra, por estar situado em antiga área de mineração, as trilhas são compostas por pedras soltas, o que leva ser classificada como Percurso por Trilhas Escalonadas ou Terrenos Irregulares; o trecho Garrida, foi classificado como sendo trecho por caminhos sem obstáculos, pois o caminho é bem marcado e de piso relativamente bom. Assim, o percurso foi classificado como Percurso por Trilhas Escalonadas ou Terrenos Irregulares. No entanto, devem ser mencionados a presença de dois trechos de superfície plana e um de caminho bem marcado, (Tabela 3).

Para finalizar o percurso, e analisar o critério Intensidade do Esforço Físico, calculou-se separadamente cada trecho obtendo dois números por trecho, sendo eles: o tempo caminhando na horizontal e a somatória dos tempos caminhado em locais íngremes ou com declives. O cálculo dos trechos do percurso, após a somatória, resultou no índice de 6,57 que, transformado em horas, chega-se ao tempo de 6:34h, que é o tempo total do percurso, incluindo o tempo das paradas, a influência das variações altimétricas e a velocidade empregada.

Assim, a Travessia Canteiros-Letreiros foi classificada como sendo uma caminhada de Esforço Intenso, (Tabela 4).

O resultado da aplicação da norma ABNT NBR 15505-02 são comunicados como segue (Quadro 3). 
Quadro 3: Painel interpretativo.

Table 3 : interpretive panel.

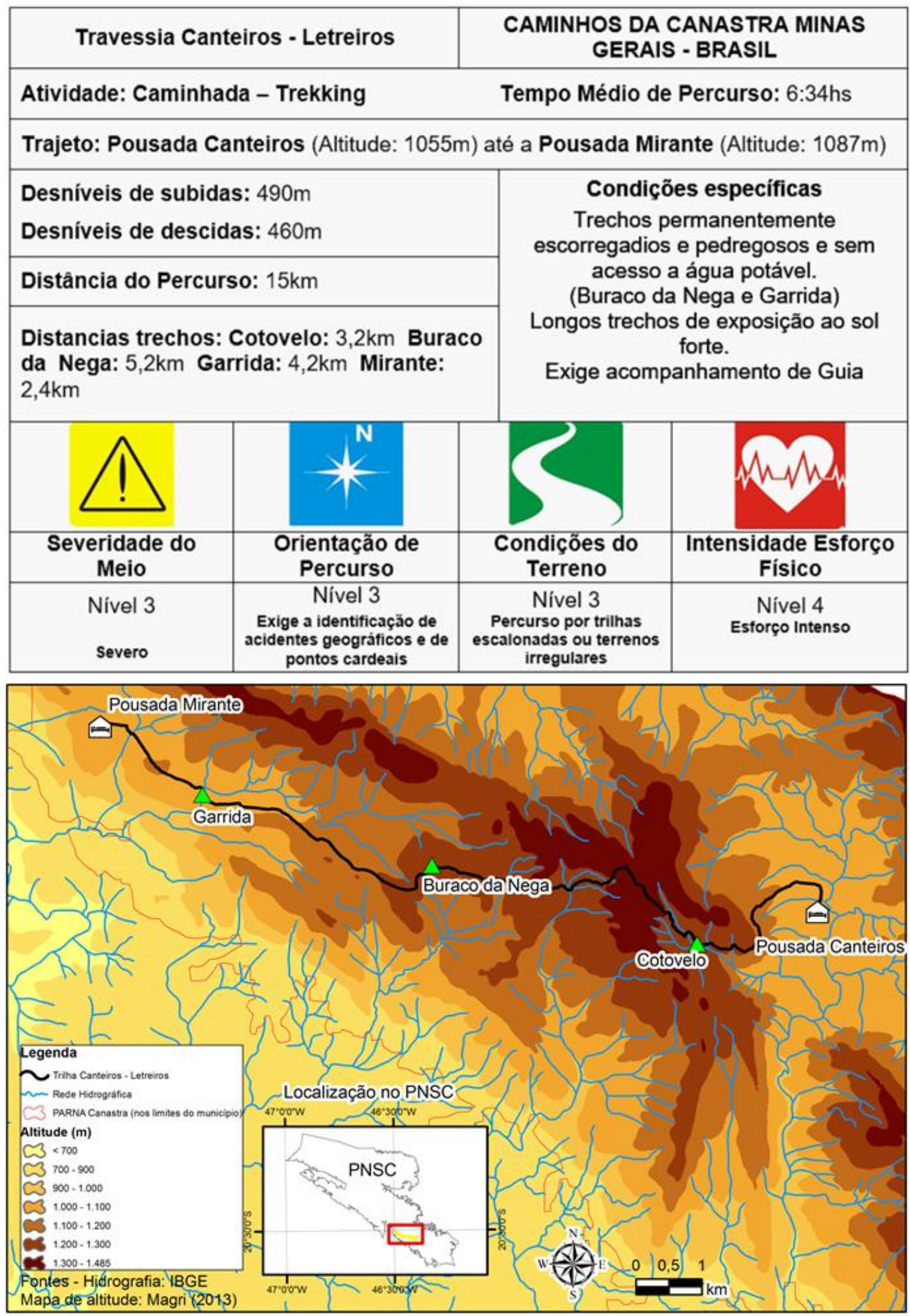




\section{Trilha Letreiros - Quilombo}

A nomenclatura criada para o percurso foi da Trilha Letreiros - Quilombo. Não foi adotado o termo travessia, pois é um percurso menor e que percorre estradas vicinais. Interpretando e analisando as informações geradas, procedeu-se seleção dos fatores e no cálculo das variantes dos critérios, que foram transcritos abaixo, para posteriormente serem repassados para o painel final de comunicação das exigências técnicas e físicas dos percursos. Foi criado um bureau de comunicação para divulgação mais detalhada ao ecoturista (Anexo 3).

No critério Severidade do Meio, o trecho Rasga Saco foi classificado como Severo; o trecho subsequente, Pousada Tia Ciça (Ribeirão Grande) foi classificado como Moderadamente Severo e o trecho Quilombo como Pouco Severo. Assim, o resultado da Trilha Letreiros-Quilombo no quesito severidade do meio, foi Moderadamente Severo, (Tabela 1).

No critério Orientação de Percurso, os trechos Rasga Saco e Tia Ciça (Ribeirão Grande) são compostos por trilhas bem definidas e caminhos bem marcados, sem muita possibilidade de atalhos, o que resulta em Caminho ou Sinalização que indica a continuidade. O trecho Quilombo foi diagnosticado como Caminhos e cruzamentos bem definidos. Assim, a Trilha Letreiros-Quilombo foi classificada como Caminho ou Sinalização que indica a continuidade, ou seja, é uma trilha mais fácil de percorrer, porém não se descarta a presença de guia de turismo no trajeto, pois o trecho Rasga Saco exige conhecimento da região (Tabela 2).

Já no critério Condições do Terreno o trecho Rasga Saco foi definido como Percurso por Trilhas Escalonadas ou Terrenos Irregulares; o trecho Pousada Tia Ciça (Ribeirão Grande) foi classificado como Percurso por caminhos sem obstáculos, e o trecho Quilombo como Percurso em superfícies Planas. Assim, o resultado final do critério condições do terreno, o percurso foi classificado como Percurso por Trilhas Escalonadas ou Terrenos Irregulares, mas deve ser mencionada a presença de dois trechos de superfície plana e sem obstáculos, (Tabela 3).

Para finalizar o percurso da Trilha Letreiros-Quilombo, foi analisado o critério Intensidade do Esforço Físico. Calculou-se separadamente cada trecho. O cálculo dos três trechos do percurso, Rasga Saco, Pousada Tia Ciça (Ribeirão Grande) e Quilombo, após a somatória, resultou no índice de 3,63 que, transformado em horas, chega-se ao tempo de 3:38 h, que se refere ao tempo total do percurso, incluindo o tempo das paradas para descanso e lanche, a influência das variações altimétricas e a velocidade empregada.

Assim, a Travessia Letreiros-Quilombo foi classificada como sendo uma caminhada de Esforço Significativo, (Tabela 4).

O resultado da aplicação da norma ABNT NBR 15505-02 são comunicados como segue (Quadro 4). 
Quadro 4: Painel interpretativo.

Table 4 : interpretive panel.

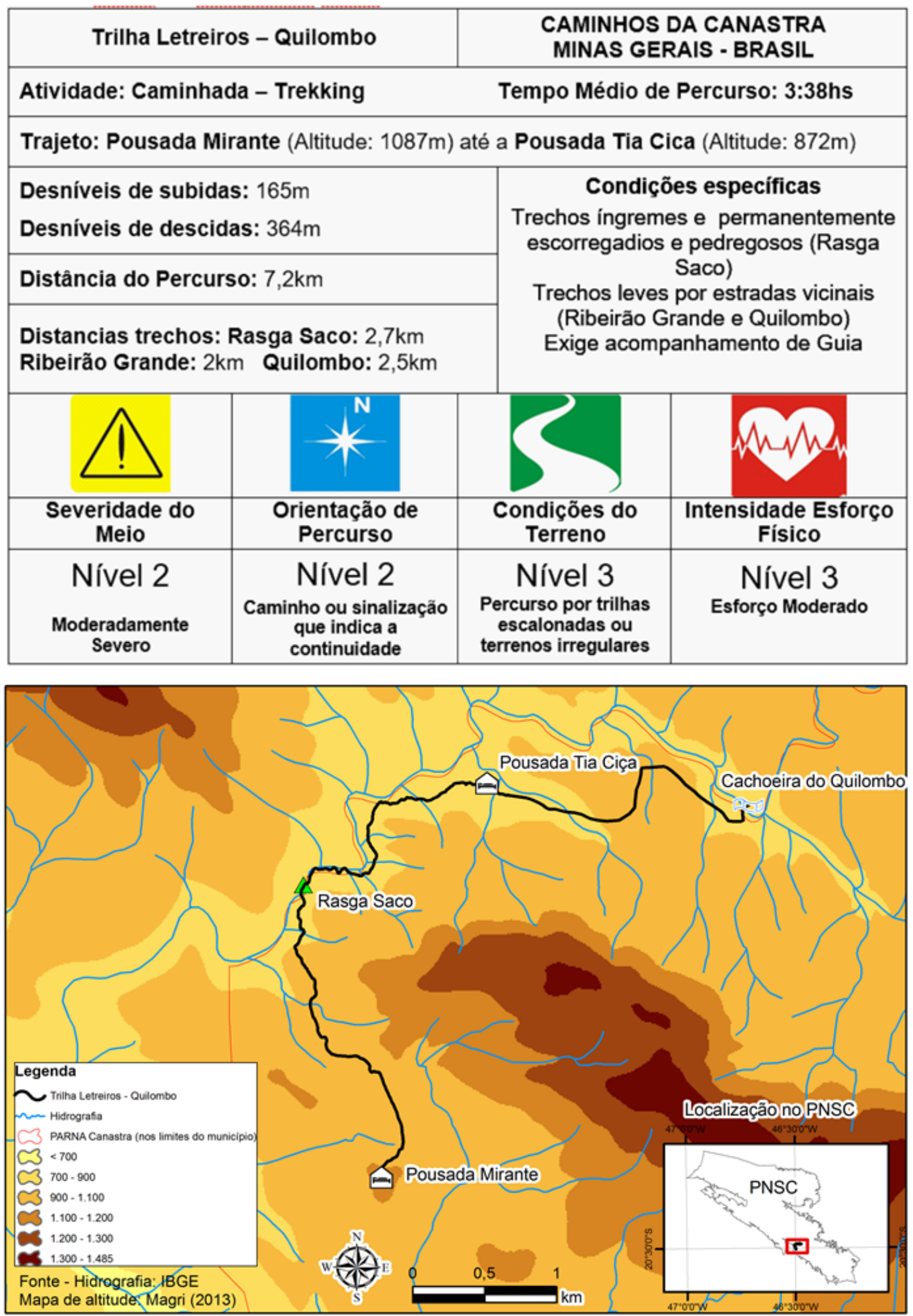




\section{Considerações finais}

Pautado na busca pelo desenvolvimento sustentável de uma área vulnerável e de extremo valor ambiental, a pesquisa ação culminou com o planejamento de um produto turístico para o desenvolvimento econômico do município de São João Batista do Glória-MG.

Durante as pesquisas houve a aglutinação de importantes empreendimentos turísticos da região, que apoiaram a concepção e deram ênfase na criação da rota Caminhos da Canastra. Os eventos testes realizados na fase preliminar confirmaram o grande potencial que, combinados em forma de roteiros, mostraram que podem ser instrumentos decisivos para alavancar o fluxo turístico, bem como para disseminar a conservação do meio ambiente pela presença de ecoturistas conscientes.

Os dados levantados e as informações produzidas embasarão um novo produto turístico e facilitará sua disseminação, gerando potenciais parcerias com operadoras turísticas de renome nacional. Isso porque se cria uma imagem de organização e profissionalismo na atividade, transmitindo confiança e credibilidade para quem pretende comercializar o produto.

A busca por destinos turísticos formatados e roteirizados é uma vertente atual dentro do Mercado Ecoturístico Brasileiro, o que credencia a Rota Caminhos da Canastra como um produto inédito a ser lançado na área de ampliação do Parque Nacional da Serra da Canastra.

Durante a execução da pesquisa, outras ramificações foram descobertas e vislumbradas, podendo ser facilmente encampadas ao eixo principal da rota, contemplando mais atrativos e ampliando a abrangência de empreendimentos e famílias residentes na área. Esta expansão poderá seguir em direção aos municípios de Delfinópolis, São Roque de Minas e Vargem Bonita, já na parte regulamentada do Parque Nacional da Serra da Canastra.

Assim, os dados poderão compor um planejamento maior, inclusive com a participação do ICMBio, que amplie e dinamize a rota com meios interpretativos, e consolide o desenvolvimento da região com atividades sustentáveis, o que possibilita novas formas de renda para empreendimentos locais com qualidade de vida.

\section{Referências bibliográficas}

ABETA Associação Brasileira de Turismo de Aventura. Diagnóstico do Turismo de Aventura no Brasil. 2009. Disponível em: http://www.abeta.com.br/ptbr/pgn.asp?id pg=65\&nivel=2; Acesso: 22/07/2015

ABNT - Associação Brasileira de Normas Técnicas. ABNT, NBR 15505-2. Turismo com atividades de caminhada. Parte 2: Classificação de percursos. Rio de Janeiro. 2008.

BOECHAT G. V. L.; ANDRADE S. R. de. A religiosidade católica e a peregrinação: um estudo de caso acerca do roteiro Fé na Estrada - Lunardelli/Apucarana - PR. Anais. Congresso Internacional de História. Maringá-PR. 2009. Disponível em: http://www.pph.uem.br/cih/anais/trabalhos/786.pdf . Acesso:12/08/2015.

CAMARGO, J.C.P; BERNARDES, L.A. O perfil do praticante de caminhadas em meios naturais, trekking, que residem na capital e grande São Paulo. Anais. V Congresso Brasileiro de Atividades de Aventura. São Bernardo do Campo-SP. 2010. 
CARNEIRO, S. M. C. de S. No Caminho de Santiago de Compostela: significados e passagens no itinerário comum europeu. Anais. IV Reunião de Antropologia do Mercosul - $\quad$ Curitiba-PR, 2001. Disponível em: http://www.caminhodesantiago.com.br/estudos/sandra.htm Acesso: 10/08/2015.

CASTRO, A. P. de. Efeito da disponibilidade de água na composição e função de comunidades microbianas presentes no solo do cerrado revelado por análises metagenômicas. 2013. 127 f., il. Tese. Universidade de Brasília, Brasília, 2013. Disponível http://repositorio.unb.br/bitstream/10482/14955/1/2013 AlinnePereiraCastro.pdf em: Acesso em: 21/08/2014.

EICHENBERG, F. O.; SILVA, C. A. da. Políticas Públicas de Turismo no Brasil: Normalização mm Turismo de Natureza e a experiência do Programa Aventura Segura. Revista de Investigación em Turismo y Desarrollo Local. v. 6, n. 15. 2013.

GOUVEIA, L.A.; GOSLING, M.; COELHO, M.F.; PEREIRA, G.A. Fatores que influenciam a intenção de compra de viagens de ecoturismo e turismo de aventura. Revista Brasileira de Ecoturismo, São Paulo, v.7, n.3, ago/out 2014, p.551-575. 2014.

ICMBIO. Instituto Chico Mendes da Biodiversidade. Plano de Manejo, Resumo Executivo: Parque Nacional da Serra da Canastra. Ministério do Meio Ambiente. 2005.

ICMBIO. Instituto Chico Mendes da Biodiversidade. Website. http://www.icmbio.gov.br/portal/ Ministério do Meio Ambiente. 2015.

MAGRI, R. A. F. Análise da suscetibilidade à erosão da região do Médio Rio Grande (MG). 2013. Dissertação (Mestrado em Geotecnia) - Escola de Engenharia de São Carlos, Universidade de São Paulo, São Carlos, 2013. Disponível em http://www.teses.usp.br/teses/disponiveis/18/18132/tde-28082013-091459/pt-br.php.

Acesso: 20/08/2015

MENDES, A.C. Peregrinos a Santiago de Compostela: Uma Etnografia do Caminho Português. Dissertação. Mestrado em Antropologia Social e Cultural. Instituto de Ciências Sociais Universidade de Lisboa. 2009. Disponível em: http://repositorio.ul.pt/bitstream/10451/299/1/20587 ulsd dep.17914 M 1.pdf.

Acesso: 16/07/2015

MENEZES, P.C. Sinalização de Trilhas: Guia Prático. 2014

OLIVEIRA, S.D.; COVALAN, A.C.; A Certificação do Turismo de Aventura no Brasil e o papel das Universidades no contexto da operação segura e responsável. Anais. V Seminário de Pesquisa em Turismo do MERCOSUL - Caxias do Sul-RS, 2008.

PAULA, S.F; CASTRO, P.T.A. Geomorfologia antropogênica em função da mineração de ouro no século XVIII: bases científicas e educativas na proposição de uma Trilha Geoturística Urbana na Sede no Município de Ouro Preto (MG). Revista Brasileira de Ecoturismo, São Paulo, v.8, n.4, mai/ago 2015, pp.432-443.

PENTEADO, H.D. Meio Ambiente e Formação de Professores. São Paulo: Cortez, 1994.

REBELLO, A. J. O Desenvolvimento da Resiliência por meio de Caminhadas de Pequeno e Longo Curso - Trekking. Revista Desenvolvimento Pessoal. v.2. 2012.

SOUZA, M.R.A.; RODRIGUEZ, M.V.; STUTZEL A.P.G. Certificação de pessoas na Área de Turismo: Estratégia de Gestão para melhoria dos Serviços Turísticos. Anais. IV Congresso Nacional de Excelência em Gestão Responsabilidade Socioambiental das Organizações Brasileiras. Niteroi, RJ. 2008. 
SPINK M. J. P.; ARAGAKI S. S.; ALVES M, P. Da exacerbação dos sentidos no encontro com a natureza: contrastando esportes radicais e turismo de aventura. Psicologia: Reflexão e Crítica. v.18, n.1 , p. 26-38. Porto Alegre, 2005.

SPINOLA, C.A. Parques nacionais, conservação da natureza e inserção social: uma realidade possível em quatro exemplos de cogestão. Revista Turismo Visão e Ação - Eletrônica, v.15, n. 1, p. 71-83, 2013.

STEIL, C.A.; CARNEIRO, S. de S. Peregrinação, Turismo e Nova Era: Caminhos de Santiago de Compostela no Brasil. Religião e Sociedade, Rio de Janeiro, v.28, n.1, p.: 105-124, 2008.

\section{Agradecimentos}

À Universidade Estado de Minas Gerais - UEMG, Unidade Passos, pela oportunidade de cursar o Mestrado Profissional em Desenvolvimento Regional e Meio Ambiente, o qual foi possível o desenvolver um trabalho inédito na região contribuindo para o desenvolvimento local e regional. Aos gestores públicos do município de São João Batista do Glória, a Prefeitura e Conselho de Turismo - COMTUR, e aos empreendedores hoteleiros envolvidos por apoiarem a iniciativa do estudo e se mostrarem dispostos a ajudar e participar do projeto, os quais são peças estratégicas na disseminação das informações obtidas.

Conrado Oliveira de Pádua Andrade: Universidade do Estado de Minas Gerais, Passos, MG, Brasil.

E-mail: conradoopa@hotmail.com

Link para o currículo Lattes: http://lattes.cnpq.br/3403754408630379

Rita de Cássia Ribeiro Carvalho: Universidade do Estado de Minas Gerais, Passos, MG, Brasil.

E-mail: ritarcarvalho@uol.com.br

Link para o currículo Lattes: http://lattes.cnpq.br/2395028352435935

Ricardo Ferreira Godinho: Universidade do Estado de Minas Gerais, Passos, MG, Brasil.

E-mail: ricardogodinho@uol.com.br

Link para o currículo Lattes: http://lattes.cnpq.br/9352275250506883

Rômulo Amaral Faustino Magri: Universidade do Estado de Minas Gerais, Passos, MG, Brasil.

E-mail: romulomagri@hotmail.com

Link para o currículo Lattes: http://lattes.cnpq.br/2764812313034086

Data de submissão: 30 de outubro de 2015

Data de recebimento de correções: 09 de maio de 2016

Data do aceite: 09 de maio de 2016

Avaliado anonimamente 


\section{ANEXOS \\ ANEXO 1 - BUREAU DE COMUNICAÇÃO DOS PERCURSOS TRAVESSIA FURNAS -CANTEIROS}

O Ponto Inicial do percurso é o empreendimento turístico Paraíso Perdido, que está situado praticamente em cima da linha que delimita a área de estudo e próximo a Usina Hidrelétrica de Furnas, 4,5km da rodovia MG-050, é um local bastante conhecido por suas formações rochosas e canyons no leito do Ribeirão Quebra Anzol, que originam dezenas de piscinas naturais de águas cristalinas. O local é um empreendimento ecologicamente correto e faz o papel de conservar a área para as gerações futuras. Existe infraestrutura como área de camping, banheiros, estacionamento, restaurante e apoio para iniciar a caminhada. Os proprietários e funcionários são treinados e sensibilizados para a causa ambiental e são instruídos para orientar as pessoas que vão utilizar a rota.

O Trecho de caminhada segue por estrada vicinal de pouquíssimo tráfego, utilizada somente por alguns sitiantes que vivem numa pequena faixa acima do Paraíso Perdido. $O$ leito da estrada segue entre a Serra do Cigano e o Ribeirão Quebra Anzol, norteando a localização. No local conhecido como "Vikings" está uma famosa cachoeira: o Paraíso Proibido, que pode ser aproveitada para uma parada para banho ou mesmo para visualizála em seu mirante natural. O empreendimento está em fase de consolidação e pode compor um futuro ponto de apoio aos ecoturistas.

Na sequência, o caminho se torna ermo e com poucas localidades habitadas, sendo possível ver casas desocupadas e currais improvisados para o manejo de criações domésticas. A partir deste ponto não há edificações ou sinais antrópicos até se visualizar o mirante do Vale dos Canteiros. Seguindo a trilha que se norteia pelo topo da Serra do Cigano à esquerda, um enorme paredão de pedra composta de cerrado rupestre. Há locais encharcadiços no caminho que se parecem com veredas, locais ideais para interação com a natureza e sentir a sensação de estar em um lugar que raríssimas vezes recebe pessoas.

Após atravessar um grande campo limpo, um grande desnível se apresenta: o Mirante do Vale dos Canteiros. O ponto é estratégico para apreciar a paisagem e fazer um lanche sob pés de arnica. Um muro de pedras, feito por antigos fazendeiros para demarcar suas terras é a referencia da trilha, perfazendo um trajeto mais suave para a descida, que não exige grandes esforços. Após adentrar o Vale, que está a mais de 1000m de altitude, existem pequenas fazendas e sítios e a partir daí há alguns colchetes e passagens em áreas habitadas por estes fazendeiros e sitiantes. Logo à frente, tem acesso à estrada principal, que segue até a Pousada Vale dos Canteiros.

\section{ANEXO 2 - BUREAU DE COMUNICAÇÃO DOS PERCURSOS TRAVESSIA CANTEIROS - LETREIROS}

O segundo trecho do percurso da rota foi nomeado de Travessia Canteiros Letreiros pois o percurso liga a região do Vale dos Canteiros até a região conhecida como Letreiros, um sitio arqueológico com inscrições rupestres. Começa na Pousada Vale dos Canteiros, uma pousada pioneira no ecoturismo, que é considerada um ícone local. Administrada por Sr Joaquim "Maruca" e seus familiares, a antiga fazenda foi aos poucos se adaptando, e hoje tem no ecoturismo sua principal atividade. Gastronomia típica, hospitalidade e convívio harmonioso são as marcas do lugar, que é considerado o Guardião do Vale dos Canteiros.

O caminho segue pela estrada vicinal sentido São João Batista do Glória, e logo após passar a entrada da Cachoeira do Barulho em uma curva acentuada conhecida como "cotovelo" entra em uma trilha estilo single track onde se percorre um antigo caminho de pedreiras abandonadas. O caminho leva ao alto da serra onde uma vasta chapada se abre, perfazendo o inicio da Serra das Palmeiras. Segue-se sempre norteando a esquerda por 
entre a crista da Serra, podendo observar o Vale dos Canteiros e a Serra da Babilônia à direita. A partir deste ponto a presença de resquícios de atividade mineradora e extratora de rochas quartzito é visível, já que, clandestinamente, o local foi incisivamente degradado. Hoje, com o fim das atividades, a natureza já dá mostras de regeneração do meio ambiente.

Segue por trilha mais larga, frequentemente utilizada por jipeiros e motoqueiros, tendo como pano de fundo sempre o Vale do Rio Grande, a cidade de Passos e um infinito horizonte.

No decorrer da caminhada paredões surgem, emolduram a paisagem e criam enormes portais que levam o nome de Buraco da Nega. Existem pontos de água, que param de jorrar na época da seca e grandes campos limpos no alto da Serra. Logo chega a região dos Letreiros, que é um sitio arqueológico com pinturas rupestres, que está localizado no prolongamento do Ribeirão que colhe as águas do alto da Serra. O destino é a Pousada Mirante, estrategicamente situada no alto

\section{ANEXO 3 - BUREAU DE COMUNICAÇÃO DOS PERCURSOS TRILHA LETREIROS - QUILOMBO}

O terceiro trecho do percurso tem início na Pousada Mirante, que se situa no alto da Serra das Palmeiras, na região dos Letreiros, em um dos pouquíssimos hectares de terras agricultáveis no local. Dali tem-se uma visão panorâmica privilegiada do Vale do Rio Grande e da Serra de Santa Maria. A caminhada segue pelos fundos da pousada, e adentra uma antiga trilha de tropeiros que levavam mantimentos para o Vale da Babilônia, conhecida como trilha do "Rasga Saco". Este nome foi dado devido a trilha ser íngreme, profunda, com paredes de pedras nas bordas, que, segundo os moradores locais, os animais carregados com mantimentos se esbarravam nestas paredes pedregosas, rasgando os sacos de mantimentos.

Após a descida, depara-se com o Ribeirão Grande, um caudaloso e imponente manancial da região, que mansamente percorre o seu caminho em direção ao Rio Grande. Ali fica a cachoeira Rasga Saco, que é um grande desnível que forma um "salto" do Ribeirão. Depois de adentrar o vale e margear o Ribeirão Grande, a trilha desemboca numa estrada vicinal pouco utilizada, por onde segue a calha do rio, sentido norte passando por pequenos sítios até chegar na Pousada da "Tia Ciça", que é o ponto de apoio desta trilha.

Duzentos metros à frente da pousada está a Vinícola Relena. A Vinícola é uma joia rara da Canastra e produz diversos tipos cortes de vinho com as mais variadas espécies de uvas, como Tannat, Chardonnay, Pinot Noir, Cabernet Sauvignon, Syrah e Merlot que se adaptaram extremamente bem na região e compõe um grande diferencial no percurso. Continuando a trilha pela estrada vicinal, passando por outros sítios, um que chama a atenção e se avista da estrada é uma tradicional Casa de Pedra, construída com técnicas rudimentares e que certamente é um exemplar único na Canastra. Logo a frente tem-se outro espetáculo da Serra da Canastra, a Cachoeira do Quilombo. A cachoeira se forma num desnível de mais de $130 \mathrm{~m}$ de altura em forma de uma grande escadaria que faz às vezes de um grande ralo por onde escorre toda a água que jorra no Vale da Babilônia. 